\title{
Source variability and recall of auditory material'
}

\author{
PAUL BAKAN AHD JAY O. THOMAS
}

MICHIGAN STATE UNIVERSITY

Recall of auditory narrative material was measured under three conditions of presentation. These were a single source condition with material from one speaker, a four source fixed sequence condition with material from four speakers in a fixed sequence of 3-sec. lengths, and a four source random condition with material from four speakers in a random sequence of 3-sec. lengths. Recall was better for the single source condition than for the four source conditions. No significant difference was found between the fixed and random sequential presentations. Results are discussed in terms of the attentional behaviors involved in the tasks.

A number of experiments have utilized spatial separation of speakers in the study of auditory attention (Poulton, 1956; Broadbent, 1954). Broadbent (1958) has concluded that spatial separation of channels or messages, produced by separating the speakers conveying the messages, is helpful in situations where the listener is to ignore one channel and respond to another.

Spatial separation of the message source appears to favor the psychological separation of more than one simultaneous message. The present study was designed to study the efficiency of attention to a single message as a function of changes in the location of the source in the course of the message. Immediate recall of narrative material was compared under three conditions of source variability over the course of the message. In one condition there was no source variability, the entire message coming from one speaker. In addition, there were two variable source conditions, where the message came sequentially from four speakers in either a fixed or a random sequence.

\section{Method}

Three groups of Ss were tested individually on recall of three tape recorded paragraphs of narrative material. $S$ sat in the center of a room containing four speakers, equidistant from his head. Speakers were placed in front, behind, to the right and to the left of $S$.

$\mathrm{Ss}$ in the single source group $(\mathrm{N}=13)$ heard the material from one speaker mounted in front of the room. A second group, the four source fixed sequence group $(N=13)$, heard the same material from four speakers in a flxed sequence of 3-sec. lengths. The first $3 \mathrm{sec}$. of the material came from the speaker in front of $S$ (Speaker 1), the next 3 sec. from the speaker to his right (Speaker 2), the next 3 sec. from the speaker behind him (Speaker 3), and the next from the speaker to his left (Speaker 4), and so on until the end of the paragraph. The message came sequentially from all four speakers in a fixed order:
$1,2,3,4,1,2,3,4$, etc. The third group $(N=16)$ listened in a four source random sequence condition. Like the $\mathrm{Ss}$ in the fixed sequence group, these Ss heard the message sequentially in 3-sec. lengths from four speakers, but the sequence of speakers was random, the same random sequence being used for all Ss in the group.

All of the speakers were of equal volume. The switch from one speaker to another was instantaneous and there was no inter ruption of the material in switching. There were no extraneous switching noises and no apparent change of intelligibility during switching.

Each $S$ listened to three passages of narrative material. The order of passages was the same for all Ss. The first two passages were taken from the Wechsler Memory Scale, form 1 (Wechsler, 1945), and the third from the FR-CR Test for evaluation of brain injury (International Psychological Service Center, 1949). The passage names and durations are Anna Thompson, 25 sec., Ship Story, 20 sec., and Normandy Beachhead, 40 sec.

Immediately after hearing each passage, $S$ was asked to tell $E$ as much as he could recall about the passage. E scored by circling predetermined idea units on a mimeographed reproduction of the passage. Following the free recall of the material from each passage, $E$ asked $S$ seven questions about the content and details of the passage. Each question could be scored as right or wrong. Ss were told to pay close attention to the passages and knew they would be tested for recall.

Ss were all males, a heterogeneous group of VA hospital employees. The passages were recorded by the junior author in male voice.

\section{Results}

Two measures of recall were analyzed for each passage, the number of idea units correctly recalled, and the number of questions correctly answered. The results are summarized in Table 1 for each passage under the three listening conditions.

Inspection of Table 1 shows that for all three passages performance on both recall tasks, free recall and questions, is better when the passage comes from one speaker than when it comes from four speakers in fixed sequence. On the basis of t-tests between the single source and the fixed sequence condition, the difference is significant at beyond the .01 level for all three passages on the free recall measure and for the first two passages on the number of questions (out of 7) answered correctly. The difference was not significant for the questions measure on the third 
Table 1. Mean Recall Measures

Passage

\begin{tabular}{|c|c|c|c|c|c|c|}
\hline \multirow[b]{2}{*}{$\begin{array}{l}\text { Listening } \\
\text { Condition }\end{array}$} & \multicolumn{2}{|c|}{ Anna Thompson } & \multicolumn{2}{|c|}{ Ship Story } & \multicolumn{2}{|c|}{$\begin{array}{l}\text { Normandy } \\
\text { Beachhead }\end{array}$} \\
\hline & $\begin{array}{c}\text { Free } \\
\text { Recall }\end{array}$ & Questions & $\begin{array}{l}\text { Free } \\
\text { Recall }\end{array}$ & Questions & $\begin{array}{l}\text { Free } \\
\text { Recall }\end{array}$ & Questions \\
\hline $\begin{array}{l}\text { Single } \\
\text { Source } \\
\text { Fixed }\end{array}$ & 10.55 & 4.92 & 9.15 & 4.46 & 13.92 & 4.77 \\
\hline $\begin{array}{l}\text { Sequence } \\
\text { Random }\end{array}$ & 6.00 & 3.54 & 5.38 & 2.62 & 7.23 & 4.15 \\
\hline Sequence & 5.75 & 3.31 & 4.31 & 2.44 & 6.44 & 2.94 \\
\hline $\begin{array}{l}\text { Maximum s } \\
\text { possible }\end{array}$ & $\begin{array}{l}\text { core } \\
23\end{array}$ & 7 & 21 & 7 & 29 & 7 \\
\hline
\end{tabular}

passage, though it was in the same direction as the other differences. The difference between the single source condition and the random sequence condition is significant at the .01 level for all comparisons. There is a slight superiority of the fixed sequence over the random sequence condition for both retention measures on all three passages. This difference is significant at the .05 level for the questions measure for the third passage (Normandy Beachhead), but for no other comparisons.

\section{Discussion}

The results indicate that spatial variability of the message source produces a decrement in immediate recall. This appears to result from a decrease in the efficiency of attention. The type of source variability, i.e., whether it is fixed or random sequence seems to have a very small effect in contrast to the presence or absence of source variability.

The spatial variability of the source may impose an additional task on the $S$, resulting in reduced capacity to process the information so as to facilitate its recall. For example, the multiplicity of sources of parts of the message may serve to break up the psychological unity of the message. The unity may have to be reconstituted by $\mathrm{S}$ before the information can be effectively processed. It would follow from this analysis that further operations serving to break up the unity would produce further decrements in recall. For example, if each speaker emitted a voice of different quality or loudness, thus further breaking up the message by adding voice variability to spatial variability, then still more decrement might occur. The unity might also be broken up by having sequential voice changes from a single speaker.

Another way in which the spatial variability might impose an additional task on $S$ can be conceived of in terms of the components of the attention response. The typical initial response to a stimulus is an orientation toward the source of the stimulation; this is followed by attention to the stimulus content, i.e., a "where is it" component is followed by a "what is it" component. If this is the case, changing the location of the source of the message elicits more orienting reactions, thus leaving less time for processing the information conveyed by the message. It would follow from this analysis that a reduction in the number of changes of position, e.g., speaker switch every 5 sec. instead of every $3 \mathrm{sec}$, would reduce the number of positional orienting responses, and consequently the decrement in recall. In essence, this is an interference explanation of the findings. The spatial orienting responses interfere with the processing of the information necessary for recall.

A question that arises is the possible effect of practice in listening to messages with variable source positions. Would the inefficient processing, inferred from poor recall, be eliminated with practice? There is no evidence of improvement during the course of this experiment, but with only $85 \mathrm{sec}$. of listening, improvement would be unlikely. The literature on orienting responses (Lynn, 1966) suggests that the orienting response decreases and shows habituation as the novelty of the stimulus decreases. Therefore, it might be expected that with continued practice in listening to a multi-source message, there might be a decrease in the orienting component of the attention response and a return to more efficient processing of the content of the message.

\section{References}

Broadbent, D. E. The role of auditory localization in attention and memory span. J. exp. Psychol., 1954, 47, 191-196.

Broadbent, D. E. Perception and communication. ĹLondon: Pergamon, 1958.

International Psychological Service Center. The FR-CR test with quantitative and qualitative check list for clinical use in the evaluation of brain injury. Psychol. Serv. Cent. J., 1949, 1, 52-61.

Lynn, R. Attention, arousal and the orientation reaction. London: Pergamon Press, 1966.

Poulton, E. C. Listening to overlapping calls. J. exp. Psychol., 1956, 52, 334-339.

Wechsler, D. A standardized memory scale for clinical use. $J$. Psychol., 1945, 19, 87-95.

\section{Note}

1. This research was conducted at the Veterans Administration Hospital, Battle Creek, Michigan. We wish to thank Dr. Stewart G. Armitage for his cooperation.

(Accepted for publication September 29, 1966.) 